\title{
Obstructive apnoeas in Duchenne muscular dystrophy
}

\author{
Yasmin Khan, John Z Heckmatt
}

\begin{abstract}
Background - In order to clarify the treatment of sleep hypoxaemias in Duchenne muscular dystrophy polysomnographic studies were performed on patients at home with the purpose of recruiting them into two clinical therapeutic trials. Observations concerning the nature of sleep hypoxaemia in these patients are presented.

Methods - Twenty one non-ambulant patients with Duchenne muscular dystrophy aged 13-23 years with no symptoms of sleep hypoventilation or apnoea were studied for two consecutive nights with eight channel polysomnography. A comparative study was performed in 12 age matched normal male subjects. The evolution of sleep hypoxaemia with age was studied in 14 patients with Duchenne muscular dystrophy.

Results - Thirteen of the 21 patients had hypoxaemia below $90 \%$ during sleep, and 12 of the 13 had discrete hypoxaemic dips in association with apnoeas; $60 \%$ of all apnoeas were obstructive in nature. The hypoxaemic periods became more frequent with increasing age and, in two patients at three year follow up, were more frequently associated with central or possibly "pseudocentral" apnoeas. Although the normal subjects had a few apnoeic episodes, none had sleep hypoxaemia below $90 \%$ saturation.

Conclusion - The sleep related breathing abnormality in Duchenne muscular dystrophy is initially obstructive and this has implications for management.
\end{abstract}

(Thorax 1994;49:157-161)

Several studies have indicated the presence of asymptomatic hypoxaemia during sleep in non-ambulant patients with Duchenne muscular dystrophy. ${ }^{1-5}$ It remains uncertain whether this hypoxaemia eventually causes symptoms or an early mortality since these patients may also have significant and independent cardiac disease. ${ }^{6}$ The question of treatment of the hypoxaemia has not been fully addressed as little is known of its pathophysiology or natural history.

In an attempt to answer these questions we studied a cohort of patients with Duchenne muscular dystrophy to ascertain those who had sleep hypoxaemia. This was preliminary to entering these patients into two controlled trials of treatment: a short term double blind trial of slow release theophylline, and a long term randomised trial of prophylactic intermittent positive pressure ventilation by nasal mask. In this paper we describe our initial polysomnographic observations on the pathophysiology of sleep hypoxaemia in this disorder, a parallel study of healthy adolescent male controls, and follow up studies showing the evolution of hypoxaemia in the patients with Duchenne muscular dystrophy with increasing age.

\section{Methods}

PATIENTS

Twenty one non-ambulant patients with Duchenne muscular dystrophy attending the Muscle Clinic at the Hammersmith Hospital were studied. All had typical disease confirmed by grossly elevated serum creatine phosphokinase activity, abnormal muscle biopsy, and loss of ambulation by their 13th birthday. All patients had their diagnostic muscle biopsies performed before dystrophin analysis became available, but 12 had undergone gene deletions. ${ }^{7}$ Their mean age was 15 years (range 13-23). Ten patients had undergone spinal stabilising surgery $\left(\right.$ Luque $^{8}$ ) for scoliosis, and three others were awaiting operation. In an attempt to identify those who may be symptomatic, all patients completed a questionnaire designed to elicit symptoms of sleep hypoventilation or apnoea including difficulty in getting to sleep, number of awakenings, snoring, nightmares, early morning headaches, daytime sleepiness, and recurrent chest infections. This questionnaire was analysed blind by one of the authors (JZH). No patient had respiratory infection at the time of the study.

Vital capacity was measured with a portable spirometer (Micromedical, Rochester, Kent, UK) in the sitting and supine positions and expressed as a percentage of the expected normal value. ${ }^{9}$ Body mass index was calculated as weight $/ \mathrm{arm} \mathrm{span}{ }^{2}\left(\mathrm{~kg} / \mathrm{m}^{2}\right) .{ }^{10}$

Sleep studies were performed with an eightchannel Oxford Medilog multiparameter recorder which is the size of a small attache case. The eight channels comprised four standard sleep montage with $\mathrm{Ag} / \mathrm{AgCl}$ electrodes and four respiratory channels as follows: EEG channel $\mathrm{C} 4-\mathrm{A} 1$, right supraorbital and left infraorbital electro-oculogram channels and submental electromyogram, thoracoabdominal movements by inductance plethysmography (Respibands; Ambulatory Monitoring Inc, Ardsley, New York, USA), air flow by oronasal thermistor, and arterial oxygen saturation by finger oximetry (Ohmeda Biox 3700). 
Each subject was studied for two consecutive nights at home, maintaining normal lights out and lights on times. Initially one of the authors (YK) stayed overnight with the patients to supervise the study and detach the electrodes; later this proved unnecessary. Patients slept in their preferred position and were turned and repositioned as normal during the night. On the morning following the study patients were routinely asked about quality of sleep, number of awakenings, and the reasons for them.

The replay (Medilog 9000-111) was retained at the hospital. It displayed all eight channels simultaneously for visual sleep staging and assessment of respiration and oxygen saturation. Additionally, an online SS-90 MK 111 sleep stager (software version 4.82) gave a detailed hypnogram of sleep and awake episodes scored in 30 second epochs according to the criteria of Rechtschaffen and Kales, ${ }^{11}$ and simultaneous oximetry and respiration. This sleep stager has been found to correlate well with visual sleep staging. ${ }^{12}$ Anomalous results were manually checked and rescored. The full sleep study on night 2 was printed out on a conventional eight channel EEG Mingograph (Siemens) in compressed format $(6 \mathrm{~cm} / \mathrm{min})$ Selected epochs were also laser printed.

A significant hypoxaemic period was defined as a $5 \%$ or greater fall in oxygen saturation from the awake baseline with associated apnoea. The hypoxaemic events were then quantified into the number of $5-9 \%$ and $10 \%$ or greater dips per night. The incidence of hypoxaemia was compared with the vital capacity, the percentage fall in vital capacity when supine, and the body mass index.

Apnoeas were classified as central, obstructive, or mixed. ${ }^{13-16}$ Obstructive apnoea was defined as sudden cessation of oronasal airflow despite continuing respiratory efforts followed by an equally rapid recovery. Central apnoea or hypoventilation was reduction or complete cessation of oronasal airflow with a corres-
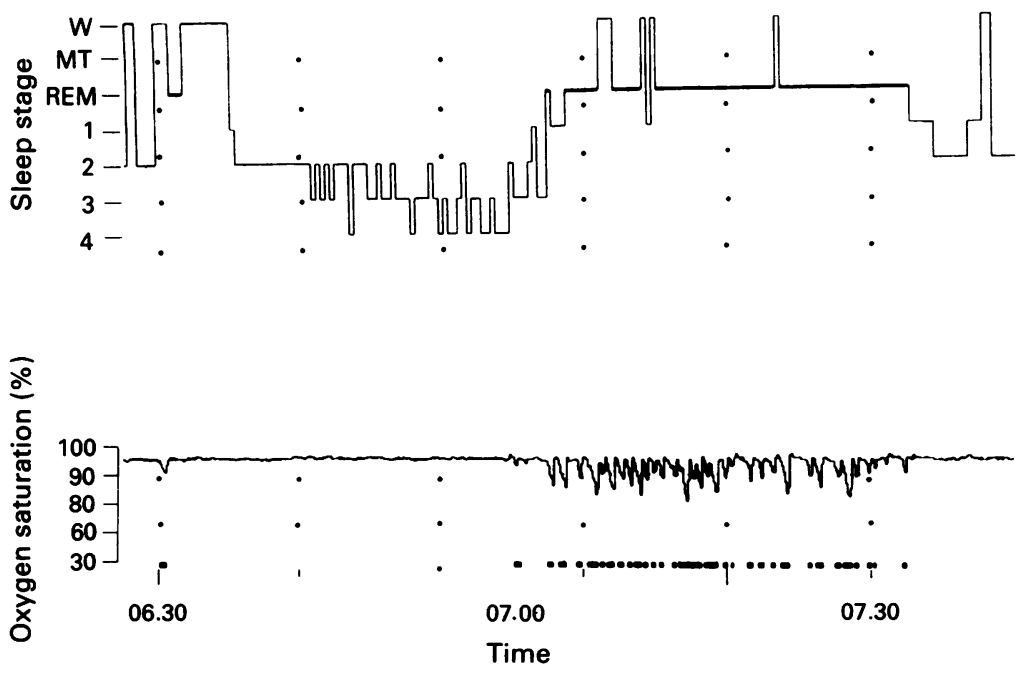

Figure 1 Section of hypnogram from 06.30 to 07.45 hours in a 16 year old patient with Duchenne muscular dystrophy showing oxygen saturation at various stages of sleep. Initially the patient has a brief arousal not associated with hypoxaemia, followed by stage 2 sleep, proceeding to stages 3 and 4 sleep, and then REM. The baseline $\mathrm{SaO}_{2}$ is $96 \%$. There is a cluster of $5 \%$ and $>10 \%$ hypoxaemic dips during $R E M$ sleep lasting 40 minutes (time base $=15$ minutes). $M T=$ movement time; $W=$ wakefulness. ponding reduction or absence of respiratory excursions, often with a gradual onset and recovery. Mixed apnoeas were a combination of the two. Only apnoeas of 10 seconds or more were analysed.

Repeat sleep studies were performed on 14 of the 21 patients. Seven were followed for $>18$ months, the longest period being three years in two patients.

The studies were approved by the hospital ethical committee and informed written consent was obtained from the patients, their parents, and the normal male subjects (see below). Correlations were studied using the standard correlation coefficient with the Minitab computer program (Minitab Inc, Philadelphia, USA).

\section{CONTROL SUBJECTS}

Twelve healthy adolescent males were also studied by identical methods. They had no respiratory illness and were not receiving any medication. Their average age was 14 years (range 10-22).

\section{Results}

PATIENTS

The average weight of the patients was $50.2 \mathrm{~kg}$, and the estimated mean body mass index was 16 (range $7-30$ ) $\mathrm{kg} / \mathrm{m}^{2}$ (the average normal body mass index for this age group being $\left.20 \mathrm{~kg} / \mathrm{m}^{2}\right) .{ }^{10}$ The mean seated vital capacity was $35 \%$ of the predicted value for age (range $16-52 \%$ ) with a mean fall of $8 \%$ when supine.

Automatic sleep staging with data analysis from all eight channels was possible for both nights on 16 patients. Detailed analysis of sleep, hypoxaemias, and apnoeas was virtually identical on nights 1 and 2 and we give results for night 2 only. All second night recordings on the 21 patients were satisfactory.

\section{Sleep}

Mean values for sleep were as follows: actual sleep time 439 minutes (range 361-543), REM time 84 minutes (67-135), sleep efficiency $93 \%$ (83-98\%), REM latency 157 minutes (50$245)$, and awake after sleep onset 20 minutes (10-68).

\section{Oxygen saturation}

All patients showed a fall in their $\mathrm{SaO}_{2}$ at the onset of sleep. In 20 of the 21 the fall was mild being $1-4 \%$ from an average awake baseline of $96 \%$ (range $91-98 \%$ ), and the baseline remained steady during the whole night. Twelve of the 20 showed discrete hypoxaemic dips of $5-10 \%$ below the baseline and, of these, 10 had dips $>10 \%$. Most of these dips occurred in clusters during REM sleep, the average number/hour being six during REM sleep and one in non-REM sleep (fig 1). Oxygen saturation during the hypoxaemic dips frequently fell below $90 \%$, the average percentage of sleep time spent with saturation below this level being $2 \cdot 4 \%$. The oldest patient (23 
years) was atypical, showing a significant fall of $12 \%$ from an awake baseline of $90 \%$ immediately on falling asleep, with subsequent gradual fluctuations between $80 \%$ and $60 \%$.

There was a strong correlation between the severity and frequency of hypoxaemic dips and age $(p<0.005)$ and the number of years spent in the wheelchair $(p=0.005)$. Only three of the 11 patients aged 14 years or younger had hypoxaemia, while all the older patients had hypoxaemia. There was no correlation between the occurrence and the severity of hypoxaemic dips, the percentage vital capacity, the fall in the vital capacity when supine, or the body mass index.

Blind analysis of the prestudy sleep questionnaire did not predict hypoxaemia. This included the one patient with Duchenne muscular dystrophy who had daytime hypoxaemia and was in respiratory failure. He only complained of occasional morning headaches and some tiredness. This combination of symptoms was also recorded in three patients without hypoxaemia.

\section{Apnoeas}

The average number of apnoeas/hour of sleep (apnoea index) was 7.5 (range 3.5-11.4). With one exception all hypoxaemic patients had a combination of obstructive, mixed, and central apnoeas, but obstruction predominated in seven. The mean percentage of obstructive apnoeas was $60 \%(10-92 \%)$, mixed $10 \%$, and central $30 \%$. Five had intermittent paradoxical movements of chest and abdomen, which were often of high amplitude, immediately before and following the apnoeic events

\section{A}

$\mathrm{SaO}_{2}$

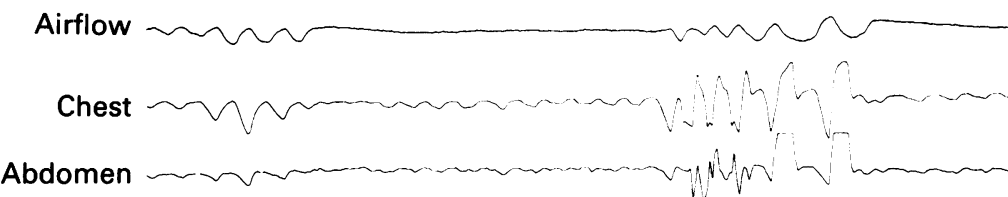

\section{$10 \mathrm{~s}$}

B

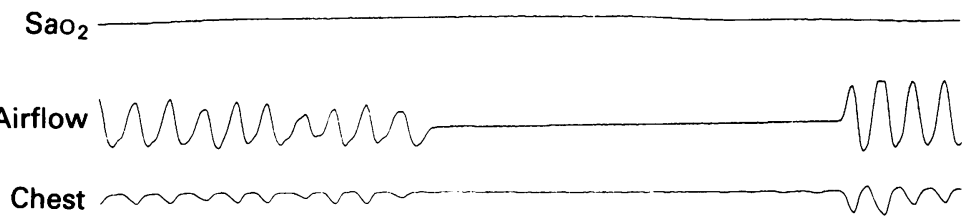

Abdomen

$$
10 \mathrm{~s}
$$

Figure 2 (A) Obstructive apnoeas associated with hypoxaemia occurring during REM sleep at 07.00 hours (from same recording as fig 1). The first apnoeic episode is characterised by a sudden cessation of oronasal airflow while low amplitude chest and abdominal movements continue. High amplitude paradoxical chest and abdominal wall movements follow the first episode. The fall in oxygen saturation lags slightly behind the apnoea. (B) Follow up sleep study in the same patient three years later showing a typical hypoxaemic apnoea. On this occasion chest and abdominal movements ceased during the apnoea. Rib cage movements are paradoxical before and after the apnoea, as they were throughout most of the night. Sleep channels were not recorded on this occasion. (fig 2A). The apnoeas occurred in clusters during REM sleep in association with the hypoxaemic dips. The continuously hypoxaemic patient had no obstructive apnoeas but had periodic breathing.

\section{Awakenings}

Few awake epochs of 30 seconds or more occurred during or after REM sleep (average one per night, range $0-8$ ). The number of awakenings remembered by the patients varied from none to 14 per night and were for repositioning.

\section{Follow up}

Ten of the originally hypoxaemic patients had repeat sleep studies; nine had many more frequent hypoxaemic dips on follow up (fig 3). Two patients, both followed for three years, showed a progressive fall in the proportion of obstructive apnoeas, from $90 \%$ to $20 \%$ in one (fig $2 \mathrm{~B}$ ), and from $60 \%$ to $30 \%$ in the other. Four of the originally non-hypoxaemic patients had follow up studies and one had developed hypoxaemic dips (fig 3 ). The patient who was continuously hypoxaemic died two months after his sleep study.

\section{CONTROL SUBJECTS}

The prestudy questionnaire did not elicit any symptoms of sleep hypoventilation or apnoea. Automatic sleep staging was possible in all 12, and the two nights of study gave similar results. The sleep data were also similar to the patients with Duchenne muscular dystrophy, mean values being: actual sleep time 404 minutes (range 288-510), REM time 67 minutes (28-155), sleep efficiency $92 \%$ (82$98 \%$ ), REM latency 69 minutes (40-150), and awake period after sleep onset 31 minutes (663). The average awake baseline $\mathrm{SaO}_{2}$ was $98 \%$ $(97-100 \%)$, and the fall at onset of sleep was $0-3 \%$; none desaturated to $<90 \%$.

Analysis of respiration showed that 11 subjects had apnoeas during the night, the pre-
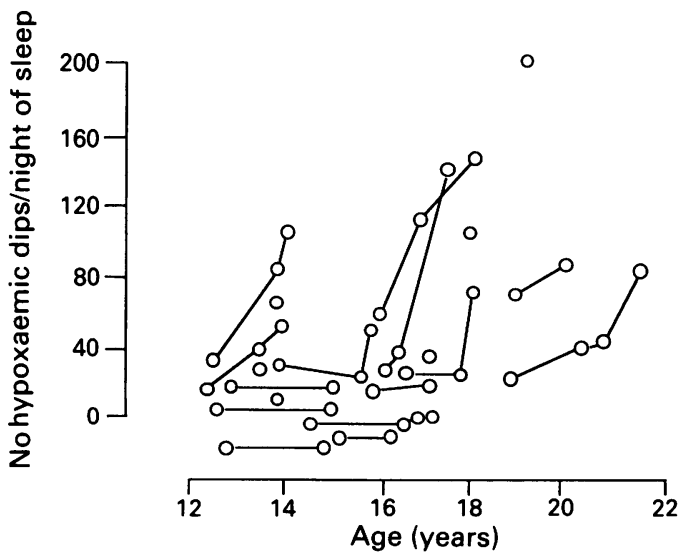

Figure 3 Relation between age and frequency of hypoxaemic dips during sleep in 20 patients with Duchenne muscular dystrophy. Nine of the 14 patients who were followed up showed that the frequency of hypoxaemic dips increased with age. (This figure excludes the 23 year old patient with continuous sleep hypoxaemia. 
dominant type of apnoea being central although one had obstructive apnoeas. The mean apnoea index was 2.9 /hour of sleep (range $0.9-4 \cdot 3$ ) and there was no clustering. The subject with obstructive apnoeas showed two hypoxaemic dips of $5 \%$ below the baseline of $96 \%$.

\section{Discussion}

The original purpose of our study was to recruit patients for a clinical trial. When the study was designed the nature and significance of the disturbed breathing during sleep was uncertain. Redding et al, ${ }^{17}$ studying five patients with Duchenne muscular dystrophy aged 13-17 years, reported intermittent hypoventilation but no apnoeas and no desaturation. Manni et $a l$ reported infrequent central apnoeas with desaturation in six of 11 patients with Duchenne muscular dystrophy aged 10-21 years, and postulated that the hypoxaemia arose as a result of the restrictive lung defect rather than the severity of the apnoeas. Smith et $a l^{1}$ reported desaturation during REM sleep in nine out of 14 patients with Duchenne muscular dystrophy aged 1522 years, and the sleep disordered breathing constituted mainly hypopnoeas with greater attenuation of rib cage than abdominal movements. Central apnoeas occurred in eight, chest wall paradox occurred in one but not in association with apnoeas, and continued electromyographic activity was seen throughout REM related, apparently central, apnoeas in two. This persistent electromyographic activity prompted the authors to suggest an obstructive aetiology.

A later study ${ }^{2}$ of six patients with Duchenne muscular dystrophy aged 16-22 years showed that diaphragm dysfunction, reflected by abdominal paradox during non-REM sleep, was predictive of the development of oxygen desaturation during REM periods. An abnormal increase in upper airway resistance, diaphragmatic weakness, or a combination of the two might have been responsible for the dysfunction. Oxygen treatment prolonged apnoeas, perhaps by converting central to obstructive apnoea, by suppression of upper airway tone, thus supporting the notion of an obstructive contribution. ${ }^{4}$ Stradling ${ }^{18}$ suggested that obstructive sleep apnoea could be mislabelled as central when weak respiratory muscles could not move the chest wall against a closed pharynx, and Smith et al coined the term "pseudocentral apnoea." The latter also reported partial reversal of apnoeas with continuous positive airway pressure, further implying a contribution by the upper airways.

Our study provides further evidence of an obstructive rather than a central aetiology, because all but one of our hypoxaemic patients had apnoeas in association with persistence of chest wall movement, and sometimes with abdominal and rib cage paradox which was often of high amplitude. We cannot easily explain why previous authors have not reported similar findings. One possibility is that, as we studied younger patients than
Smith and coworkers, our patients might have been better able to generate respiratory excursions in the presence of upper airways obstruction. This is supported by the evolution with age of apnoeas from obstructive to apparently central in two of our patients followed up for the longest period (three years).

The only way of resolving this issue would be to measure transdiaphragmatic pressures during sleep. We wished to minimise instrumentation of our subjects in order to recruit sufficient numbers for clinical trials. We have subsequently tried to persuade our patients to swallow oesophageal balloons for respiratory function tests, but without success. Nevertheless, using non-invasive techniques, it is more likely that obstructive apnoeas would be mistaken for central, rather than the reverse. ${ }^{19}$

The hypoxaemic apnoeas observed in our patients are likely to be of pathological significance. Apnoeas are less common in normal subjects of the same age and sex. Our finding of both central and obstructive apnoeas in healthy adolescent males corroborates those of previous workers, but both clustering of the apnoeas and an accompanying fall in oxygen saturation below $90 \%$ are uncommon. ${ }^{20-22}$ Furthermore, sequential studies in our patients showed that the hypoxaemias become more frequent and severe with age, although none had continuous hypoxaemia on follow up. We are not certain that the continuous hypoxaemia we observed in our oldest patient represents an "end stage" of the discrete hypoxaemic dips of the others, or whether another factor was operating in him, in particular cardiac involvement. ${ }^{623}$

Our desire to perform controlled trials has arisen out of the increasing use of ventilation for Duchenne muscular dystrophy ${ }^{24}$ and the claim by Rideau and coworkers that night time nasal ventilation preserves lung function. ${ }^{26} \mathrm{We}$ studied Duchenne patients with relatively mild asymptomatic hypoxaemia on the assumption that the hypoxaemia would be progressive and eventually lead to symptoms. We could not perform clinical trials in patients with Duchenne muscular dystrophy presenting with symptomatic sleep apnoea because of the likelihood of including patients in near terminal respiratory failure. Although our one patient with chronic respiratory failure did not have related symptoms, we have treated selected patients for symptomatic respiratory failure with nasal ventilation. ${ }^{27}$

We do not recommend routine sleep studies in asymptomatic non-ambulant patients with Duchenne muscular dystrophy unless some prophylactic treatment is planned which, at present, should be in the context of a controlled clinical trial. Abolition of REM sleep by protriptyline was effective in preventing hypoxaemia, but the drug was not tolerated, ${ }^{28}$ and there seems to be no acceptable pharmacological means of abolishing REM sleep. The obstructive aetiology suggests that any method of prophylaxis would have to be mechanical rather than pharmacological.

This project was supported by the Muscular Dystrophy Group of Great Britain and the Handicapped Children's Aid Commit- 
tee. The authors thank Professor V Dubowitz for his help and encouragement during the course of the study, and are grateful to Dr John Stradling, Consultant Physician, Osler Chest Unit, Churchill Hospital, Oxford, for assistance with data interpretation.

1 Smith PEM, Calverley PMA, Edwards RHT. Hypoxaemia during sleep in Duchenne muscular dystrophy. Am Rev

Respir Dis 1988;137:884-8.
2 Smith PEM, Edwards RHT, Calverley PMA. Ventilation and breathing pattern during sleep in Duchenne muscular dystrophy. Chest 1989;96:1346-51.

3 Manni R, Ottolini A, Cerveri I, Bruschi C, Zoia MC, Lanzi $\mathrm{G}$, et al. Breathing patterns and $\mathrm{HbSaO}_{2}$ changes during nocturnal sleep in patients with Duchenne's muscular dystrophy. $\mathcal{F}$ Neurol 1989;236:391-4.

4 Smith PEM, Edwards RHT, Calverley PMA. Oxygen treatment of sleep hypoxaemia in Duchenne muscular dystrophy. Thorax 1989;44:997-1001.

5 Smith PEM, Edwards RHT, Calverley PMA. Mechanisms of sleep disordered breathing in chronic neuromuscular disease: implications of management. $Q \quad \mathcal{H ~ M e d}$ 1991;296(New Series 81):961-73.

6 Hunter S. The heart in muscular dystrophy. Br Med Bull 1990;36:133-5.

7 Hodgson S, Hart K, Abbs S, Heckmatt J, Rodillo E, Bobrow $\mathrm{M}$, et al. Correlation of clinical and deletion data in Duchenne and Becker muscular dystrophy. $f \mathrm{Med}$ Genet 1989;26:682-93.

8 Luque ER. Segmental spinal instrumentation for correction of scoliosis. Clin Orthop 1982;163:192-8.

9 Godfrey S, Kamburoft PL, Nairn JR, Connolly NMC, Godfrey S, Kamburoft PL, Nairn JR, Connolly NMC,
Davis J, Packham E, et al. Spirometry, lung volumes and airway resistance in normal children aged 5-18 years. $\mathrm{Br} \mathcal{F}$ Dis Chest 1970;64:15-24.

10 Casey VA, Dwyer JT, Coleman KA, Valadian I. Body mass index from childhood to middle age: a 50-year follow-up. Am $\mathcal{F}$ Clin Nutr 1992;56:14-8.

11 Rechtschaffen A, Kales A. A manual of standardised terminology, techniques, and scoring system for sleep states in
human subjects. Bethesda and Washington: US Governhuman subjects. Bethesda and Washington: US Govern-
ment Printing Office, Public Health Service, 1968:1-12.

12 Friston KJ, Sharpley AL, Solomon RA, Cown PJ. Lithium increases slow wave sleep: possible mediation by $5-\mathrm{HT}_{2}$ receptors? Psychopharmacology 1989;98:139-40.

13 Cherniack N. Respiratory dysrhythmias during sleep. $N$ Engl f Med 1981;305:325-30.

14 Baker TL. Introduction to sleep and sleep disorders. Sym- posium of sleep apnea disorders. Med Clin North Am 1985;69:1123-52.

15 Strohl KP, Cherniack N, Gothe B. Physiologic basis of therapy for sleep apnoea. Am Rev Respir Dis 1986;134:791-802.

16 Stradling JR, Phillipson EA. Breathing disorders during sleep. $Q 7$ Med 1986;225(New Series 58):3-18.

17 Redding GJ, Okamoto GJ, Guthrie RD, Rollevson D, Millstein JM. Sleep patterns in non-ambulatory boys Millstein JM. Sleep patterns in non-ambulatory boys
with Duchenne muscular dystrophy. Arch Phys Med wehabil 1985;66:818-21.

18 Stradling JR. Disorders of ventilatory control and sleep apnoea syndromes. In: Brewis RAL, Gibson GJ, Geddes $\mathrm{BM}$, eds. Respiratory medicine. London: Balliere Tindall, 1990:1352-72.

19 Staats BA, Bonekat W, Harris CD, Offord KP. Chest wall motion in sleep apnea. Am Rev Respir Dis 1984;130:5963.

20 Carskadon MA, Harvey K, Dement WC, Guilleminault C, Simmons FB, Anders TF. Respiration during sleep in children. West $f$ Med 1978;128:477-81.

21 Tabachnik E, Muller NL, Bryan AC, Levison H. Changes in ventilation and chest wall mechanics during sleep in normal adolescents. F Appl Physiol 1981;51:557-64.

22 Marcus CL, Omlin KJ, Basinki DJ, Bailey SL, Rachal AB von Pachmann WS, et al. Normal polysomnographic values for children and adolescents. Am Rev Respir Dis 1992;146:1235-9.

23 Dowdell WT, Javaheri S, McGinnis W. Cheyne-Stokes respiration presenting as sleep apnoea syndrome, clinical and polysomnographic features. Am Rev Respir Dis and polysomno

$24 \mathrm{Mohr}$ CH, Hill NS. Long-term follow-up of nocturnal ventilatory assistance in patients with respiratory failure due to Duchenne-type muscular dystrophy. Chest 1990;97:91-6.

25 Baydur A, Gilgoff I, Prentice W, Carlson M, Fischer DA. Decline in respiratory function and experience with longterm assisted ventilation in advanced Duchenne's muscular dystrophy. Chest 1990;97:884-9.

26 Rideau Y, Delaubier A. Neuromuscular respiratory deficit: setting back mortality. Semin Orthop 1987;3:203-10.

27 Heckmatt JZ, Loh L, Dubowitz V. Night-time nasal ventilation in neuromuscular disease. Lancet 1990;335:57982.

28 Smith PE, Edwards RH, Calverley PM. Protriptyline treatment of sleep hypoxaemia in Duchenne muscular dystrophy. Thorax 1989;44:1002-5. 